\title{
A Inserção dos Tranformadores de Plásticos na Cadeia Produtiva de Produtos Plásticos
}

\author{
Gabriela M. A. Padilha e José V. Bomtempo
}

Resumo: Uma cadeia produtiva pode ser definida como um sistema constituído por agentes formadores de decisão, envolvidos em um processo interdependente, por meio de um fluxo de produtos e serviços em uma direção. $\mathrm{O}$ artigo apresenta um modelo de cadeia produtiva de produtos plásticos, discutindo os seus principais atores e a inserção dos transformadores de plásticos nessa cadeia. De acordo com a inserção na cadeia produtiva, os transformadores de plásticos terão posturas diferentes em relação à inovação, marketing, gerenciamento tecnológico, oferta de serviços e outros investimentos.

Palavras-chave: Materiais plásticos, cadeia produtiva, transformação de plásticos, inserção na cadeia produtiva, relações cliente-fornecedor.

\section{Introdução}

A indústria de transformação de plásticos no Brasil compreende cerca de 5200 empresas que faturaram em 1998, aproximadamente, US\$ 12 bilhões. Foram transformados 3,3 milhões de toneladas de resinas como Polietilenos (PE), Polipropileno (PP), Poliestireno (PS), Policloreto de Vinila (PVC) e Polietileno Tereftalato (PET). Trata-se de um segmento formado por $68 \%$ de micro empresas, $24 \%$ de pequenas, $7 \%$ de médias e apenas $1 \%$ de empresas grandes (ABIPLAST, 1998) .

Pressionada pelos atores a montante (Indústria Química e Petroquímica) e pelos atores a jusante (Indústrias Automobilística, Alimentícia, Farmacêutica, Cosméticos, entre outras), a Indústria de Transformação de Plásticos vive um período de reestruturação, procurando encontrar posições competitivas que permitam explorar as oportunidades de crescimento dos materiais plásticos.
O presente trabalho tem como objetivo analisar a inserção dos transformadores na cadeia produtiva de produtos plásticos.

O trabalho está organizado da seguinte forma: inicialmente na seção 1 será apresentado um modelo de cadeia produtiva de produtos plásticos e discutidos os principais elementos dessa cadeia. $\mathrm{Na}$ seção 2 discute-se a inserção dos transformadores de plásticos nessa cadeia produtiva. Essa discussão apoia-se em grande parte em resultados de pesquisa de campo realizada juntos às empresas transformadoras no Rio de Janeiro (Padilha, 1999). Por fim, a seção 3 apresenta as conclusões do trabalho.

\section{Apresentação da cadeia produtiva de produtos plásticos}

Uma cadeia produtiva pode ser definida como um sistema constituído por agentes formadores de 
decisão envolvidos em um processo interdependente, por meio de um fluxo de produtos e serviços em uma direção. Pode envolver desde fornecedores de matéria prima, produção propriamente dita, distribuição e até consumidores finais. Todos os elementos ou níveis de uma cadeia executam funções importantes, cujos respectivos desempenhos determinam de forma interdependente o desempenho do sistema como um todo (Towill, Nam \& Wilkner apud Figueiredo, Zambom,1998).

A cadeia produtiva de produtos plásticos que está representada na Figura 1, tem início na utilização das matérias primas nafta ou gás natural para a obtenção dos produtos petroquímicos básicos. Essa conversão é feita no Brasil por três empresas que são as centrais de matérias-primas dos Pólos Petroquímicos - Pólos Petroquímicos de São Pau- lo, Camaçari e Triunfo - e constituem a Primeira Geração Petroquímica. Estão em andamento ainda projetos para a instalação de mais dois empreendimentos (Rio de Janeiro e Paulínia), para a produção de petroquímicos básicos.

Os produtos petroquímicos básicos, provenientes da primeira geração, são transferidos para as empresas da segunda geração, as quais irão transformá-los em resinas plásticas. No Brasil existem cerca de 20 empresas produtoras de resinas, a maioria localizada nos Pólos Petroquímicos.

As principais resinas termoplásticas, do ponto de vista comercial, produzidas por estas empresas são:Polietileno de Alta Densidade (PEAD); Polietileno de Baixa Densidade (PEBD); Polietileno de Baixa Densidade Linear (PEBDL); Polipropileno (PP); Poliestireno (PS); Poliestireno Expandido

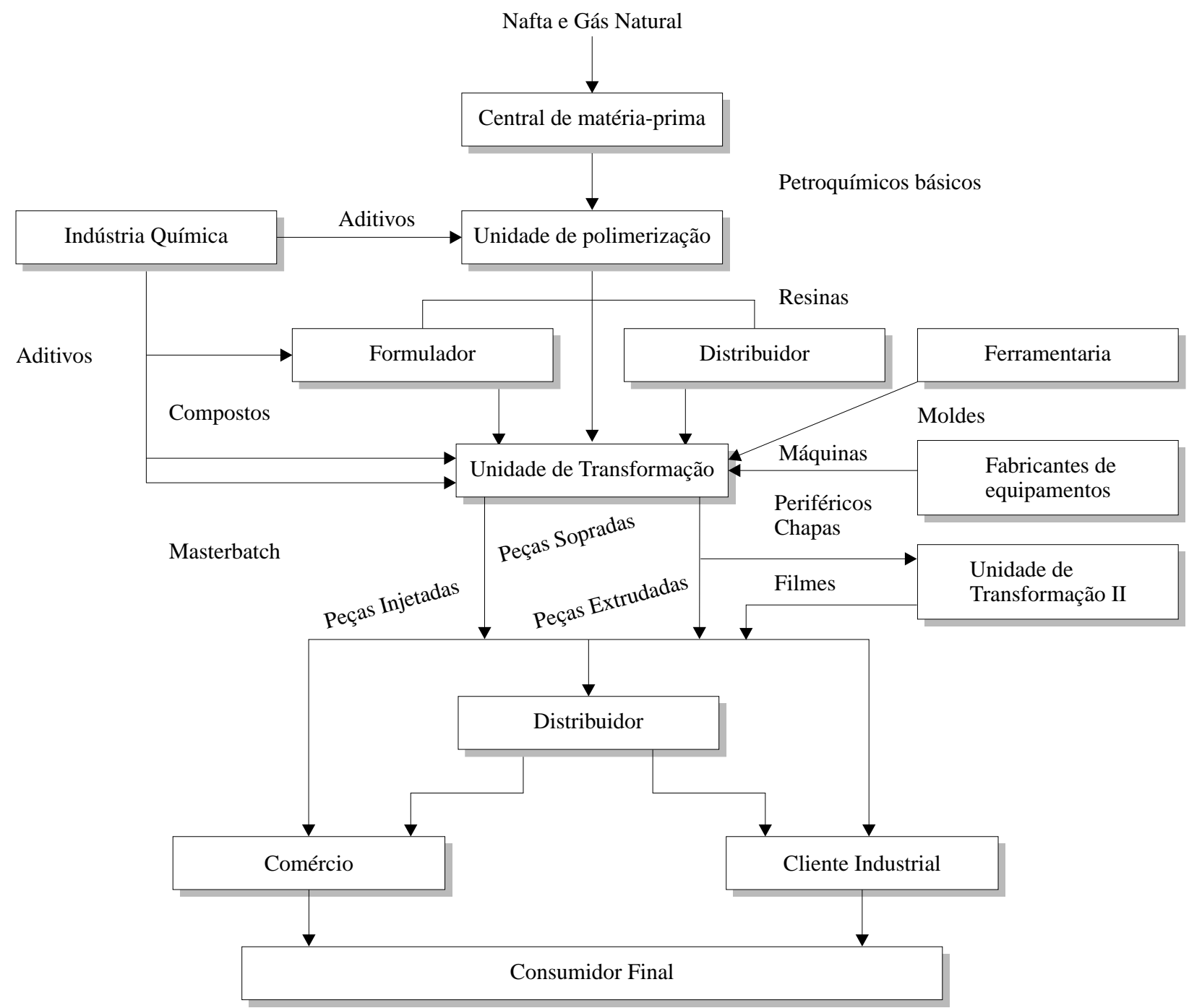

Figura 1. Cadeia Produtiva de Produtos Plásticos

Fonte: (Padilha, 1999) 
(EPS); Policloreto de Vinila (PVC); Polietileno Tereftalato (PET).

As resinas são compradas pelas empresas transformadoras de plástico, as quais irão transformálas, em geral através dos processos de extrusão, injeção, sopro, termoformagem e rotomoldagem, numa grande diversidade de produtos.

Ressalte-se que a chamada indústria de transformação de plásticos não se enquadra na definição habitual que considera indústria como um grupo de empresas fabricantes de produtos que são substitutos bastante próximos entre si. A indústria de transformação de plásticos, converte as resinas produzidas pela segunda geração, em artefatos de diferentes cores, formatos e finalidades, que atendem aos mais diversos setores da economia, tais como: setores agrícola, alimentício, automobilístico, cosméticos, construção civil, eletroeletrônico, farmacêutico, higiene e limpeza, médico- hospitalar.

O setor de transformação pode ser entendido como formado de grupos de empresas, cada um deles apresentando uma inserção peculiar na cadeia. Esses grupos têm em comum, a montante na cadeia produtiva de produtos plásticos: fornecedores de matérias-primas, equipamentos e periféricos, além dos processos básicos de produção. A jusante, entretanto, pouco têm em comum.

A Figura 2 sintetiza a apresentação da cadeia produtiva de produtos plásticos, permitindo uma visão estruturada de seus principais atores. Nessa figura, representa-se o número de empresas no Brasil em cada elo da cadeia, começando pelas centrais de matérias-primas

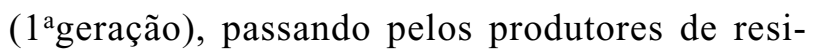
nas ( $2^{\text {a }}$ geração) e chegando aos transformado-

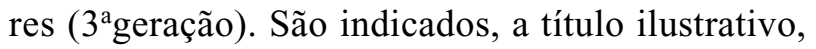
os investimentos médios para a construção de unidades de produção de eteno, polietilenos e produtos transformados.

\section{A inserção dos transformadores de plásticos na cadeia produtiva de produtos plásticos}

A postura dos transformadores na cadeia produtiva de produtos plásticos é definida principalmente pelo tipo de cliente que ele possui: clientes industriais ou clientes comerciais. De acordo com o tipo de cliente, as empresas terão comportamento diferenciado em relação à : inovação, administração de marketing, investimentos.

O setor de transformação de plásticos é, segundo a classificação de Pavitt (Tidd, Bessant, Pavitt, 1997) quanto à origem das inovações tecnológicas, um setor dominado pelos fornecedores. Em tais setores as mudanças tecnológicas são originadas pelos fornecedores de equipamentos e de insumos.

No caso do setor de transformação de plásticos, as inovações originam-se prioritariamente dos fabricantes de equipamentos, moldes, dos produtores de resinas e da indústria química.

Os fabricantes de equipamentos introduzem no setor novas possibilidades de processamento, otimizando variáveis importantes no processo de concepção de um produto plástico como: velocidade do ciclo, redução do desperdício, qualidade, economia de matéria prima e energia.

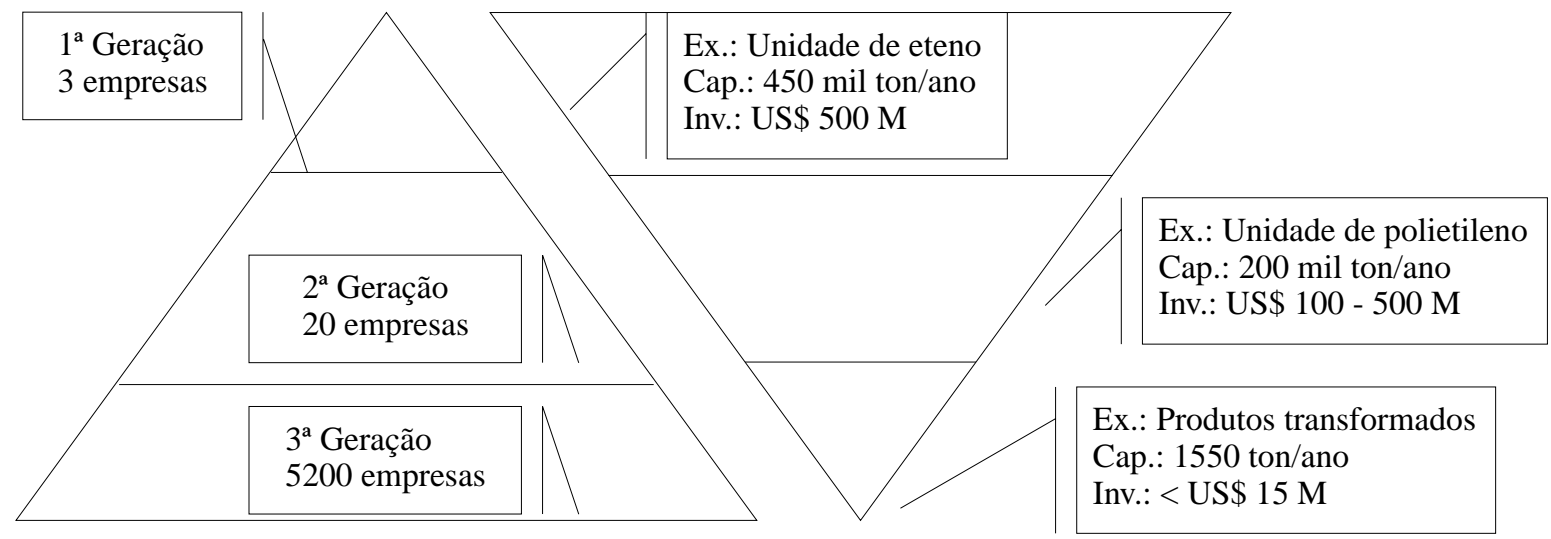

Simbolos: $\mathrm{Cap}=$ capacidade em mil toneladas/ano; Inv= investimentos em US\$; $M=$ milhões

Figura 2. Das matérias-primas petroquímicas aos produtos plásticos: número de empresas no Brasil, capacidades e investimentos típicos. (Fonte: Padilha, 1999) 
Os fabricantes de moldes permitem que peças mais complexas sejam criadas tornando as empresas de transformação mais capazes para competirem em novos campos que exigem peças mais elaboradas e com nível tecnológico mais elevado, como por exemplo o setor automobilístico.

Os produtores de resinas introduzem novos grades e novas resinas a fim de atender às necessidades existentes dos transformadores, além de, criar como os fabricantes de moldes, novas frentes para o uso do plástico, permitindo que os transformadores tornem-se mais competitivos em mercados dominados por outros materiais.

Os efeitos da indústria química refletem indiretamente nos transformadores, uma vez que as inovações propostas por ela no ramo de catalisadores e aditivos, entre outros, impulsionam os produtores de resinas para o desenvolvimento de novos produtos.

Cabe ao setor de transformação explorar as oportunidades surgidas com as inovações dos seus fornecedores e com elas desenvolver vantagens competitivas ou reforçar vantagens já conquistadas. Essas oportunidades podem estar voltadas para o produto, isto é, para o melhor atendimento das necessidades dos clientes com a oferta de produtos com melhor qualidade, maior nível tecnológico, design mais moderno, ou podem estar voltadas para o processo, isto é, para o aperfeiçoamento do processos de produção, possibilitando a oferta dos produtos especificados, dentro dos prazos estabelecidos e com um custo aceitável pelos clientes.

\section{Clientes Comerciais}

Os clientes comerciais representados pelos supermercados, lojas de departamentos, lojas especializadas. compram dos transformadores: calçados, utilidades domésticas, brinquedos, fios e cabos, produtos utilizados na construção civil (tubos, canos, conexões, etc), entre outros. Esses produtos, segundo a ABIPLAST ${ }^{1}$, representam $35 \%$ do consumo total de resinas.

O relacionamento dos transformadores ao longo da cadeia é um relacionamento que segue o modelo da Figura 3.

As setas pretas representam as relações comerciais entre fornecedores e clientes ao longo da cadeia. Enquanto que as setas vermelhas representam a existência de outros tipos de interações, além das comerciais, entre os atores da cadeia. Essas interações envolvem a troca de informações e em alguns casos, a cooperação no desenvolvimento novos produtos, serviços ou no aperfeiçoamento dos produtos existentes.

Os transformadores relacionam-se com a segunda geração de duas formas: a primeira consiste na compra da resina disponível, em uma relação puramente de mercado, e a segunda consiste no desenvolvimento conjuntivo de soluções que atendam às necessidades dos transformadores.

O comércio funciona como um elo importante entre os transformadores e os consumidores finais. As relações transformador-comércio e comércioconsumidor final são relações de mercado que priorizam as variáveis preço e qualidade.

Talvez a relação mais importante na cadeia seja a relação entre transformadores e consumidores finais. Embora não seja uma relação direta do tipo cliente-fornecedor, ela é importante para que os transformadores conheçam - através de contato com os consumidores finais, pesquisas de mercado, relatórios de vendedores - as carências, anseios e sugestões dos consumidores finais dos seus produtos. A partir desse conhecimento, os transformadores tornam-se capazes de detectar

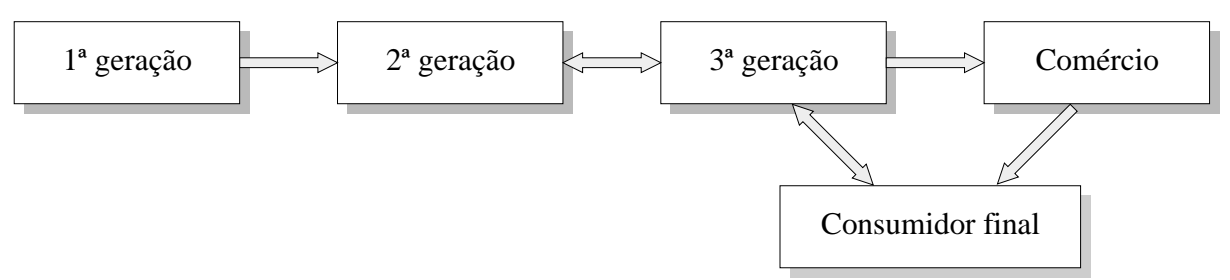

Figura 3. Relacionamentos dos atores na cadeia produtiva de transformadores com clientes comerciais

\footnotetext{
${ }^{1}$ Exposição da ABIPLAST no Seminário: Os desafios da indústria do Plástico. São Paulo, 1999.
} 
oportunidades para desenvolverem novos produtos e serviços e empreenderem melhorias nos já produzidos.

\section{Clientes industriais}

O mercado industrial consiste em todas as organizações que adquirem bens e serviços usados na produção de outros produtos ou serviços, que são vendidos, alugados ou fornecidos a terceiro. (Kotler, 1998). Esses possuem diversas características que diferem dos mercados comerciais, entre elas: presença de poucos e grandes compradores, relacionamento estreito entre fornecedor e comprador, demanda derivada da demanda por bens de consumo, demanda flutuante, compra direta. (Kotler 1998).

Os principais produtos transformados vendidos a clientes industriais são: embalagens, peças técnica, filmes e acessórios.

\section{Embalagens}

O setor de embalagens no Brasil movimenta anualmente mais de R\$ 12 bilhões. (Pinho, 1998). O material plástico vem assumindo um papel muito significativo neste mercado e segundo ABIPLAST ${ }^{1}$ corresponde a $55 \%$ do consumo total de resinas plásticas, consumindo no total aproximadamente 1,8 milhões de toneladas ano.

As embalagens plásticas atendem principalmente aos setores: alimentício, de higiene e limpeza, cosméticos, farmacêutico e industrial e são dividias em : flexíveis, rígidas e sacaria de ráfia.

De acordo com o tipo de produto acondicionado e o mercado consumidor a importância da embalagem para a comercialização do produto será diferente, embora, geralmente, ela tenha as funções de atrair a atenção, descrever as características do produto, criar confiança do consumidor e produzir uma impressão global favorável.

Alguns clientes demandam embalagens que priorizam o caráter de proteção ao produto, como é o caso das embalagens industriais como sacaria e containers. Neste caso, o transformador pode ser um agente inovador, tanto no produto quanto no processo, visando sempre a atender às necessidades do seus clientes no que tange às características físicas, químicas e mecânicas da embalagem. A escolha do produto transformado é baseado em atendimento às exigências do cliente em relação a performance da embalagem e preço.
Outros clientes que priorizam o design, a funcionalidade e a qualidade, como no caso das indústrias alimentícias, de cosméticos e farmacêutica. Embalagens bem desenhadas podem criar valor de conveniência para o consumidor e valor promocional para o fabricante dos bens de consumo. Nesse caso, a escolha pelo produto é por atendimento às especificações do produto, qualidade, preço.

A proposta da inovação da embalagem surge predominantemente do cliente, e é feita através de amostra, molde, CAD ou desenho, cabendo ao transformador a função de executar o pedido com pouco espaço para inovar no produto. Entretanto, ela pode ser introduzida também através de projetos conjuntos nos quais transformadores e clientes trabalham na elaboração da inovação, ou através do transformador que elabora a inovação.

\section{Peças Técnicas}

Nesse segmento estão agrupados os produtos destinados ao setores automobilístico, eletroeletrônico e de eletrodomésticos.

Segundo a ABIPLAST ${ }^{1}$ esse segmento responde por $10 \%$ do consumo total de resinas plásticas, que são distribuídos da seguinte forma: $5 \%$ é destinado à indústria automobilística, 3\% à indústria de eletroeletrônicos e $2 \%$ às peças industriais.

Uma das características desse segmento é o alto nível de exigências dos clientes, principalmente a indústria automobilística. Os transformadores devem atender rigorosamente às especificações técnicas e de qualidade dos produtos, para isso os transformadores que atuam nesse segmento devem possuir tecnologia avançada e competência na produção.

\section{Filmes e Acessórios}

Os setores de embalagens e peças técnicas abrem espaço para o surgimento de empresas produtoras de filmes, chapas, bobinas técnicas e acessórios como válvulas spray, alças, lacres, entre outros.

Os filmes são usados principalmente para produção de embalagens flexíveis, as chapas e perfis para a produção de peças técnicas e os acessórios são usados para compor outros produtos ou para auxiliar a performance do produto principal como por exemplo os aplicadores de cremes .

De uma forma geral os relacionamentos na cadeia produtiva para os transformadores que possuem clientes industriais apresenta a forma apresentada na Figura 4. 


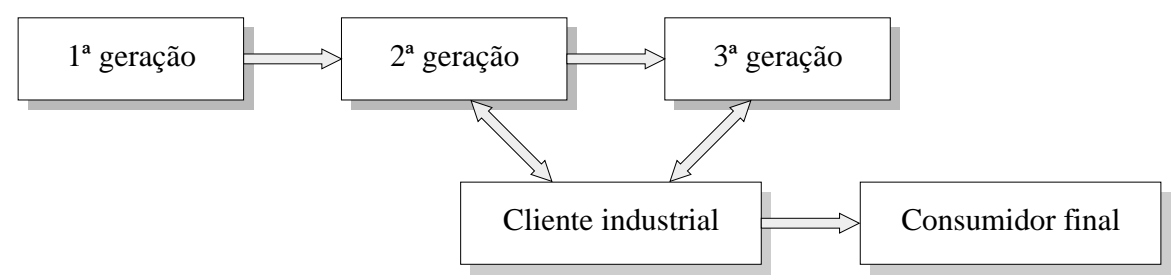

Figura 4. Relacionamentos dos atores na cadeia produtiva de transformadores com clientes industriais

Os clientes industriais desejam obter os componentes plásticos em tempo estabelecido, com uma excelente qualidade e performance exatamente de acordo com as suas expectativas. Existe atualmente uma tensão na cadeia devido à redução do número de fornecedores na maioria dos setores industriais. Sobreviverão aqueles transformadores que sustentarem uma posição competitiva em relação aos concorrentes e conseguirem estreitar o seu relacionamento com os clientes.

A interação entre segunda geração e cliente industrial, embora, não seja uma relação do tipo cliente-fornecedor é comum no desenvolvimento de soluções na busca de novos grades ou materiais, que atendam às necessidades do cliente.

Os transformadores exercem um papel de executores de tarefas, uma vez que nestes setores os pedidos tendem a chegar com todas as características especificadas, deixando pouco espaço para o transformador inovar no produto. Cabe a eles: aprimorar o processo de transformação, visando a otimização da produção e redução nos custos e principalmente ter condições tecnológicas e estruturais de atender aos pedidos dos clientes com sucesso.

As condições tecnológicas estão relacionadas aos equipamentos, e as condições estruturais relacionam-se à flexibilidade da empresas em se adaptar às mudanças do cenário competitivo, mantendo os seus clientes e conquistando novos.

\section{Conclusão}

A cadeia produtiva de produtos plásticos é influenciada principalmente pelos atores que introduzem as inovações: clientes industriais, fabricantes de resinas, equipamentos e moldes. A terceira geração embora influencie a cadeia me- nos do que esses atores, exerce umas das principais funções da cadeia que é transformar em realidade produtos especificados pelos clientes industriais e desejados pelos clientes comerciais, explorando todos os recursos tecnológicos propostos pelos outros atores da cadeia.

A peculiaridade da inserção na cadeia produtiva apresentada na seção 2 deve condicionar as iniciativas de apoio e incentivos ao setor de transformação de plásticos, assim como as estratégias dos atores da cadeia.

\section{Referências Bibliográficas}

1. Associação Brasileira da Indústria do Plástico. Perfil 98 da Indústria-Brasileira de Transformação do Plástico, São Paulo: (1998).

2. Figueiredo, R. S., Zambom, A. C. - A empresa vista como um elo da cadeia de produção e distribuição. Revista de Administração. São Paulo, v.33., n.3, pg 30, (1998).

3. Kotler, P. - Administração de Marketing:Análise, Planejamento, Implementação e Controle. 5.ed. São Paulo: Atlas, (1998).

4. Padilha, G. M. A. - Setor de Transformação de Plásticos: Caracterização e Determinação do Perfil Competitivo através da análise do setor no Rio de Janeiro. Rio de Janeiro: UFRJ, Escola de Química. Tese de Mestrado em conclusão.

5. Pinho, V. G. - A Brasilpack e as tendências mundiais da embalagem.Pack- Tecnologia e Logística de embalagem. São Paulo, n.14, p. 14-25, (1998).

6. Tidd, J., Bessant, J., Pavitt, K. - Managing Innovation. Chichester: Jonh Willey, (1997). 